\title{
"Mi dulce, mi querido, mi bello teatro crítica": Diálogo sobre la función del teatro y la crítica desde el Chile actual ${ }^{*}$
}

\author{
Andrés Kalawski** \\ Cristián Opazo** \\ Milena Grass ${ }^{* * * *}$
}

\section{Resumen}

El estado actual de la sociedad obliga a preguntarse por la función del teatro. Esta pregunta aparece en numerosas obras teatrales chilenas de dramaturgos de las nuevas generaciones. El estado de la sociedad, el del teatro y el de los medios de comunicación obliga, por ende, también a preguntarse por la función de la crítica teatral. Desde la perspectiva de tres críticos universitarios, este ensayo propone una respuesta tentativa a estas preguntas.

Palabras clave: Teatro chileno (s. xx), historia y crítica del teatro, crítica teatral.

\section{"My Sweet, my Dear, my Precious Theatre-Criticism": Dialogueonthe Function of Theatre andTheatre Criticismfrom XXI-Century Chile}

\begin{abstract}
The current state of Chilean society demands a new approach to an old question: Today, whatis the social function of theatre? This question arises in the recent production of several playwrights from the new generation. In this scenario, the state of society as well the state of theatre productions and new social media also demand a reflection on the role of theatre criticism. From our point of view, this essay offers a first (tentative and elusive) answer.
\end{abstract}

Keywords: Chilean Theatre (XX-XXI c.), History and Criticism of Chilean Theatre, Theatre Criticism.

Este artículo se inscribe, de manera simultánea, en los proyectos FONDECYT Regular1141095 y 1150483 , respectivamente.

*" Chileno. Doctor en Historia, Pontificia Universidad Católica de Chile. Profesor Asociado en la Escuela de Teatro de esa misma casa de estudios. akalawsk@uc.cl

*** Chileno. Doctor en Literatura, Pontificia Universidad Católica de Chile. Profesor Asociado en la Facultad de Letras de esa misma casa de estudios. cmopazo@uc.cl

**** Chilena. Doctora en Literatura, Pontificia Universidad Católica de Chile. Profesora Asociada en la Escuela de Teatro de esa misma casa de estudios.mgrass@uc.cl 
“El 'teatro' consiste en representar ficciones vivas de acontecimientos humanos ocurridos o inventados, con el fin de divertir"

(Bertolt Brecht)

"Ven y critícame, yo soy así. .."

(René Pérez Joglar / Residente)

\section{La pesadilla de Bobby Meyer}

La acotación que cierra el primer acto de Los invasores (1963), de Egon Wolff, avisa: “[e]n ese momento, entra Bobby [desde] el jardín impulsado por varias manos que lo empujan dentro de la habitación. Le han amarrado, fuertemente atado con cuerdas, un cartel que oprime su pecho y que dice, garabateado con letras inciertas, palabras. Un instante trastabilla por la habitación y, luego, cae en el medio de ella" (30). Parafraseemos: ante la mirada atónita de sus padres (el industrial Lucas Meyer y su esposa Pietá), un joven burgués idealista (Bobby Meyer) es maniatado por una horda de insurrectos (China, Toletole y Alibabá); con su irrupción intempestiva, los harapientos descalabran la disciplina doméstica y sus códigos constitutivos (e.g. centralidad de la propiedad privada, preeminencia de la cultura letrada, valoración del dinero). De manera mordaz, el asalto de estos "invasores" -justo diez años antes del golpe cívico-militar- pone en relieve la ingenuidad de un pupilo universitario confiado en la capacidad de representar y, con ello, resolver los conflictos entre élites (emergente burguesía industrial, relevo de la oligarquía agraria) y grupos subalternos (habitantes de "callampas" de la rivera Mapocho, desplazados desde campamentos mineros y latifundios). La "fe" de Bobby Meyer, claro está, se sustenta en su auto-celebrada capacidad para construir "artefactos lingüísticos" que aluden a esos que llevan sobrenombre en lugar de apellido: discursos, dramas, documentales, novelas o proclamas informados desde las certezas, bien intencionadas, de una la cultura letrada comprometida con las "causas sociales." ${ }^{1}$ El escarnio que padece Bobby Meyer dramatiza la pesadilla que perturba -en el texto de Wolff, de manera literal- el sueño de esa generación de creadores y críticos, formados -como dice

Estrenada en 1963, bajo la dirección de Víctor Jara y escenografía modernista de Amaya Clunes, Los invasores pone en escena a una familia de la alta burguesía chilena enfrentada a la llegada de una horda de harapientos que viven "al otro lado del río." En su encuentro, esta familia de empresarios enfrenta una experiencia de alteridad que no puede ser reducida a la figura de la caridad. 
Isidora Aguirre- en los bastidores de los teatros universitarios: que se estropee la mentada certeza que aún los alienta; a saber, que el teatro sea una representación que, por fiable, contribuya a comprender $y$, de paso, componer una comunidad nacional desgarrada -una comunidad que, en plena década de 1960, avanza a tientas entre los espectros de la Guerra Fría.

Cuales descendientes de la casta de los Meyer, nosotros investigadores teatrales situados en una universidad chilena del "dos mil"- podemos hacernos los lesos, pero no podemos soslayar el que, sin linchamientos, la pesadilla de Bobby Meyer se hizo realidad: en la segunda década del nuevo milenio, el teatro deja de ser -incluso dentro del contexto mismo universitario- el instrumento dilecto para explicar los (des)encuentros de la comunidad nacional. Bien podríamos suponer que, al igual que Bobby Meyer, creadores y críticos estamos en riesgo de ser "maniatados" y "atados" a una pancarta cuyo lema hueco es "teatro, teatro, lo tuyo es puro teatro. . . estudiado simulacro", como diría La Lupe. $\mathrm{O}$, peor aún, en riesgo de ni siquiera ser nombrados en la escena de la escritura académica. ${ }^{2}$ ¿A quién sirve el teatro, entonces? Y, en su estado actual, ¿será percibido por los individuos (marginalizados, por ejemplo) que inspiran sus representaciones como una práctica tan vacía como las diatribas de Bobby Meyer? Tenemos la impresión de que esa pregunta está siendo escamoteada. ${ }^{3}$

Desde nuestra perspectiva, la sola retórica de historias, pedagogías y críticas teatrales acusa el declive de esta pregunta: cien años antes, la voz teatro participa de una constelación tropológica en la que convive, cual sinónimo, con expresiones tales como espejo, reflejo y representación -esta última, escrita sin guion que perturbe la continuidad entre prefijo y sustantivo. Cien años después, la sinonimia es imposible. Los

Es sintomático advertir que en congresos de estudios culturales y literatura (e.g. ACLA, IILI, LASA, MLA), son cada vez menos los investigadores que reconocen en la dramaturgia o en las puestas en escena -tal como las conoce Bobby- sus objetos de estudio. A la inversa, un número cada vez más amplio de investigadores se siente más atraído por la categoría de performance y, desde ella, aprehenden como corpus de trabajo manifestaciones, en apariencia, más directamente vinculadas con los debates públicos del presente (e.g. intervenciones urbanas y manifestaciones ciudadanas).

3 Piénsese, sin ir más lejos, en la polémica con repercusión en presa que se suscita tras el anuncio de cierre del Centro de Investigación Teatral La Memoria en 2016, fundado y dirigido por el director y actor Alfredo Castro. En un intercambio de cartas, columnas e, incluso, debates parlamentarios, los tropos recurrentes fueron "financiamiento," “Estado," o "cultura." Poco se dijo de "audiencias," "función” o "alcance geográfico". Según versión de La Tercera, los teatristas “[s]olicitaban subvención permanente por cinco años para los gastos fijos de las salas con directores de trayectoria y prestigio..." (3). Un debate similar ocurriría con el cierre del Teatro de la Palabra, al año siguiente. 
desarrollos tecnológicos, los movimientos migratorios y las urgencias políticas -entre muchos otros condicionantes- desafían el léxico crítico. Ahora, desprovistos de certezas, buscamos guarecernos bajo un tejido de neologismos que, con su sentido incierto, mitigue la sombra de obsolescencia que acecha nuestro lexicón teatral: trocamos "espejo" por "holograma"; "texto" por "superficie", "teatro" por "performance”; en fin, ¿aún titularíamos el programa de un curso como teatro y sociedad? ${ }^{4}$

Más allá de nuestros fetiches léxicos, consideramos que estas mutaciones retóricas exigen ser atendidas como síntoma de la "pérdida de poder de las artes conviviales (Dubatti 25-27). O, lo que es equivalente, supone someter a escrutinio el contrato social" entre una comunidad desintegrada y el teatro que, en ella, se produce (Féral 9). ¿Qué puntos debe considerar una agenda de revisión del contrato entre teatro y cultura chilena?; ¿de qué manera la revisión contractual alterna nuestras nociones de historia, pedagogía y crítica teatrales? y, por lógica consecuencia, ¿ cómo debemos releer el canon dramatúrgico/ teatral en una encrucijada como esta? Para responder estas preguntas -ejes de este diálogo- revisaremos, de manera sucesiva, las bases del "contrato social" del teatro chileno (políticas públicas de culturas), ciertas "reacciones meta-teatrales" que encontramos en textos/ montajes recientes y, por último, algunas "instancias críticas" surgidas en el tramado cultural de ya no tan nuevo milenio.

\section{Bobby Meyer vs. el presente}

Según creemos, el sueño de Bobby y la pesadilla están determinados por un escenario histórico particular. Sirva volver sobre la escena clave, cerca de 1938: en nuestro país, la renovación teatral que ocurrió en toda Latinoamérica -en el periodo de los nacionalismos populistas que identifica Ángel Rama en La ciudad letrada- se llevó a cabo desde las

\footnotetext{
Estos nuevos tropos emergen bajo el alero de los estudios sobre performance. Los estudios sobre performance -aclaremos- enseñan conexiones entre agendas creativas y/o críticas que, de otro modo, se percibirían desagregadas. Así, bajo su alero, convergen las definiciones de dramaturgia, texto dramático y dramaturgo de Eugenio Barba (2004), Hans-Thies Lehmann (2004) y Heiner Müller (2013) que, respectivamente, sustentan nuestra postura. De Barba, recogemos el axioma que indica que la dramaturgia es una práctica escrituraria que codifica tres tipos de materiales: sensoriales, verbales e inconscientes (255-56). De Lehmann, tomamos la metáfora que figura al texto como un espacio ignoto -textscape, dirá en inglés- cuya topología desconcierta al explorador (148-50). De Müller, rescatamos la premisa de que dramaturgo es quien dispone, en la escena de la escritura, materiales que obligan a diseñar nuevas maneras de administrar el espacio teatral (26). Como resulta evidente, en este espacio crítico, el mínimo-común-denominador de las premisas de Barba, Lehmann y Müller es la sujeción a experiencias materiales (Pavis 214). Para mayores detalles, véase, Opazo, “Agorafobia: crítica: universidad.”
} 
universidades. Durante el siglo XX, el teatro, que ya había transferido su carga pedagógica desde los movimientos obreros, se acopló de manera casi perfecta a la modernización del Estado -no por azar, el lema que inaugura el periodo es "Gobernar es educar" y, por ley gramatical, "educar" es, a la vez, "gobernar." Así lo entendieron en las décadas de 1940 y 1970, los sucesivos gobiernos del Frente Popular y, luego, la Revolución en Libertad y la Unidad Popular.

En concordancia con el programa de gobierno del Frente Popular, las instituciones de educación superior establecieron una agenda de modernización del Estado (Ochsenius, passim). En el ámbito de la educación, esta agenda pro-modernización señala que la instrucción formalizada debe ser complementada por el fomento y difusión de la ciencia y de la cultura, en tanto proceso colectivo de escrutinio de la "realidad". Así, bajo el alero de las universidades de Chile, Católica y de Concepción surgen compañías de teatro, cuerpos de danza y orquestas sinfónicas. ${ }^{5}$ De manera particular, el teatro es concebido como instancia de educación cívica: frente a las tablas, los connacionales aprenderían virtudes, reconocerían defectos y se hermanarían con sus pares. Bien podría decirse que con el asenso del Frente Popular se inicia la primera gran nacionalización del periodo 1938-1973: la nacionalización del teatro. ${ }^{6}$

Para comprender los alcances de este proceso de nacionalización, nótese el siguiente ejemplo. En el número uno de la revista Teatro, publicación oficial del Teatro Experimental de la Universidad de Chile, el editorial, titulado "Propósitos," celebra el alcance nacional del teatro universitario ${ }^{7}$ :

\footnotetext{
En su novela Machos tristes, Darío Oses recrea con maestría la fulgurante vida cultural del periodo: "como lo hicieron las iglesias con sus campanarios durante la colonia fue la universidad la que después marcó el tiempo y el ritmo de la vida en la ciudad, y además le inoculó una sustancia nueva porque no solo engranajes de relojería operaban en el altillo. Los cabros del ITUCH [nombre adquirido por el TEUCH a partir de 1959, cuando se consolida como instituto de la U. de Chile] renovaron el arte dramático que hasta entonces se reducía a los galanteos de Alejandro Flores. Más allá Domingo Santa Cruz organizaba orquestas. . . mientras los maestros de danza exiliados de la Alemania Nazi preparaban las coreografías de Carmina Burana y de la Mesa verde. . . todo eso, conciertos, estrenos, sueños, manifiestos, pasaban a ser parte del lenguaje con que la ciudad hablaba, entendía y gratificaba a los hombres que vivían en ella" (71-72).

6 Proponemos la metáfora de la nacionalización, pues, durante el periodo en cuestión, el Estado, vía universidad, ofrece incentivos materiales y simbólicos para que los nuevos teatristas desarrollen su trabajo dentro de la universidad. Dentro de los incentivos, se cuentan programas de apoyo a la internacionalización, instancias de intercambio académico y concursos de dramaturgia y dirección, entre otros.

Al hojear la revista, constatamos que Teatro publica tres números: noviembre de 1945, marzo-abril de 1946 y mayo-junio 1946. Bajo la dirección de Pedro de la Barra y "en consecuencia con los principios extra-docentes de la universidad," se propone cumplir una función de escuela de espectadores, ya que
} 
La difusión teatral ha sido ampliada con jiras a provincias. En 1944 se organizó el viaje más completo que ha hecho este conjunto [TEUCH]: su jira al Sur de Chile. Actuó en las ciudades de Linares, Chillán, Los Ángeles, Temuco, Valdivia, La Unión, Osorno y Puerto Montt. Durante veinte días, saltando de un pueblo en otro, conoció diferentes públicos, diferentes maneras de reaccionar, y logró hacer surgir en todas partes un sentimiento de optimismo y de fe en el arte [dramático]... (8)

El objetivo de estas caravanas culturales distintivas del TEUCH, iniciadas en 1942 e inspiradas en las misiones pedagógicas (1931-1936) de Alejandro Casona, era llevar el teatro hacia nuevos públicos. Las giras -enseguida replicadas por el Teatro Ensayo de la Universidad Católica (TEUC)- son un ejemplo elocuente de la tarea que las universidades chilenas le asignan a sus teatros-academias: cartografiar conocer, (re) construir una comunidad nacional en torno a la experiencia de escribir, montar y ver teatro. ${ }^{8}$

Bien sabemos que, en 1973, la dictadura no solo interrumpe este proceso de educación y gobierno desde el teatro, sino que destruye las coordenadas simbólicas que dan sentido a un teatro de vocación pública y nacional. ${ }^{9}$ En este escenario, el teatro que viene después se convierte en refugio, en espacio de sobrevivencia, en un lugar donde establecer una solidaridad primaria dominada por la reunión de los cuerpos. El epitafio lo escribe, con justicia, Hernán Vidal (1998):

Durante las primeras etapas del régimen militar la oposición se expresó a través de actos culturales altamente ritualizados. . . funciones de teatro de algunas de las compañías independientes

\footnotetext{
"en Chile, el espectador concurre a los espectáculos teatrales desprovisto de puntos de referencia... esenciales para gustar y juzgar lo que ve" ("Propósitos" 3).

8 Hemos observado la emergencia de una genuina cruzada geográfica en estos teatros. Anótense algunos ejemplos: Las pascualas (1957) y Los que van quedando en el camino (1969), de Aguirre (laguna sureña [Región del BíoBío] y fundo en Ranquil [Región de La Araucanía]); El Cherube (1965) y La remolienda (1965), de Sieveking (volcanes andinos [Región de La Araucanía] y colina en las cercanías de Villarrica y burdel en Curanilape [Región de la Araucanía]); La isla de los bucaneros (1944), de Bunster (caleta extraviada en los mares del Pacífico Sur [Chile insular]); Ayayema (1964) y Fuerte Bulnes (1955), de Requena (Isla Wellington [Región de Magallanes]); y, también, El abanderado (1962), El tony chico (1964) y Versos de ciego (1961), de Heiremans (valles transversales [Región de Valparaíso]) (Opazo, "Luis Alberto Heiremans: las seducciones del paisaje").

“Teatros públicos" ya que el objetivo común de estas compañías universitarias es, además de formar académicos/ creadores, contribuir a la formación de audiencias, diversas y transversales, en regiones desatendidas tanto por las compañías comerciales como por las políticas de Estado (De la Barra cit. en Opazo).
} 
que todavía operaban. . . El clima emocional predominante en estas funciones era de tierno afecto, preocupación y confianza en el prójimo. El cuerpo humano se convirtió en el eje de esta sensibilidad. . . Por un largo tiempo estos actos culturales sirvieron a la oposición para mantener contacto y reconstruir una identidad política truncada, para renovar contactos, para reorganizarse. (125)

Agreguemos para cerrar que la imagen de teatro-refugio es replicada por los espacios que con recurrencia figuran textos y montajes del periodo: chozas en ruinas de tomas obreras (El loco y la triste, de Juan Radrigán), residuos urbanos (Cinema Utopía, de Ramón Griffero), departamentos clandestinos (Nadie es profeta en su espejo, Jorge Díaz). Después del fervor de los teatros universitarios, después de la atomización de los teatros bajo dictadura, ¿dónde queda nuestro oficio?

\section{La palabra que se escribe hoy: ¡malestar!}

Cincuenta años después del linchamiento de Bobby Meyer, en la Política de fomento del teatro (2010-2015) del Gobierno de Chile se leen signos de desconfianza, obsolescencia y, sobre todo, malestar: "[aquí] [e]l concepto de texto no es asumido como obra literaria sino que dentro de una puesta en escena o puesta en voz [ya] que el ejercicio teatral fundamental en relación con el texto es su representación escénica" (10). El que un documento gubernamental se afane en precisar-amparado en la autoridad de Patrice Pavis- lo que es propio del texto dramático y la relación que debe guardar con el teatro da cuenta del malestar que, hoy día, suscita la palabra teatro: por un lado, el mercado, con la complicidad del Estado, reclama un teatro de entretenimiento (emancipado en su financiamiento, ojalá); por otro, el Estado, cuando no cómplice, se afana en "usarlo" como prueba cuantificable de su gestión cultural (se cuentan becas, se cuentan estrenos y "audiencias", se cuentan salas). Los creadores, en el descampado, defienden el estatuto artístico de sus trabajos (en tanto proceso de escrutinio de la realidad análogo a los desarrollos de la investigación científica)..$^{10}$

\footnotetext{
10 Este malestar deviene tironeo. Este tironeo se ha colado en los debates públicos sobre las leyes que permitirán la instalación de los nuevos Ministerios de Cultura, y de Ciencia y Tecnología. El proyecto de ley que crea el primero, no solo no define cultura sino que, peor aún, deja entrever que cultura -a la manera de la antigua extensión universitaria- pone en circulación efímera producciones artísticas
} 
Igualmente, en el ámbito léxico, los defensores del mercado despliegan el discurso del emprendimiento; el Estado, el de la propaganda; los creadores, por su parte, construyen sus enunciados según polémica observación de Josette Féral (2003)- de acuerdo con una genuina "retórica de la queja":

[1] os autores se quejan de no ser llevados a escena, los directores de no tener buenos textos que montar, los actores de que no hay suficiente trabajo y de estar mal pagados, los teatros de no poder correr riesgos, los críticos de no ver el teatro que quisieran aplaudir y el público de no siempre disfrutar el teatro que se les ofrece (17)."

Pasada la efervescencia de la transición, desaparecidas las antiguas funciones del teatro, vuelve la pregunta por la función, vuelve el tironeo, vuelve el malestar. La incertidumbre por la función o propósito es particularmente intensa cuando sabemos de la posición marginal del teatro respecto de la forma reproductible e inmaterial que prefiere el mercado para el consumo cultural y de la forma masiva y desterritorializada (televisión, radio, cualquier cosa que pueda habitar la internet) que prefieren los estados para su estímulo cultural.

Este malestar no se expresa solo en los debates sobre el rol del Estado respecto de la política cultural, no aparece solo en la posición incierta de las artes en las universidades, sino que brota en los escenarios, al interior del teatro mismo. Detengámonos unos minutos en algunos ejemplos sintomáticos de la dramaturgia publicada/ estrenada en la última década (2007-2017).

Comencemos con Neva (2007), de Guillermo Calderón. Allí, la dramaturgia nos sitúa "en una sala de ensayo en San Petersburgo, el domingo 22 de enero de 1905. Secundada por dos actores de oficio, la viuda de Chejov

aisladas. El segundo proyecto de ley, en tanto, emplea una retórica restrictiva que, basada en los criterios de la OCDE, deja fuera la creación teatral que se concibe como un proceso de generación de conocimiento, y no como un ejercicio de producción de espectáculos. Para mayores detalles, véase la columna de Opazo, “¿Dónde quedan las humanidades y las artes en un futuro ministerio de ciencia?” (El Mercurio, 7 ago. 2017, E6).

11 Un ejemplo de la intersección de discursos del malestar se encuentra en la polémica suscitada entre el ex-Ministro de Cultura, Luciano Cruz Coke y el teatrista Alfredo Castro. Mientras Castro reclama fondos para mantener operativo su centro de investigación teatral, Cruz Coke señala la necesidad de que los creadores busquen alianzas estratégicas con capitales privados. Según glosa la versión electrónica del diario La Tercera del 23 de abril de 2013, Cruz Coke recuerda: "[e]stamos modificando la ley de donaciones culturales para hacer más fácil la obtención del beneficio para recursos privados.” A su vez, allí mismo, Castro responde: "[p]royectos como el mío se caracterizan por su alto nivel de crítica, y es evidente que los empresarios no pondrán en riesgo su prestigio. Pensar que eso es posible es de una ingenuidad enorme." (s.r.) 
intenta" poner en voz El jardín de los cerezos. La rutina, eso sí, se ve perturbada por manifestaciones callejeras que anuncian un baño de sangre:

Afuera hay un domingo sangriento, la gente se está muriendo de hambre en la calle y tú quieres hacer una obra de teatro. [...] Me da vergüenza ser actriz. Es tan egoísta, es una trampa burguesa, un basurero, un establo de yeguas. [...] Oh, mi querido, mi dulce, mi bello teatro. El amor me da risa. El teatro es una mierda. Los actores son una mierda. Me imagino una revolución. El mundo se va a acabar y nunca vamos a ser libres. ¿Para qué perder el tiempo haciendo esto? (126-7)

Por supuesto, podemos asumir que, con astucia, la dramaturgia enuncia una pregunta retórica como una manera de diferir una respuesta que conocemos mejor de lo que quisiéramos. De manera paradójica, la pregunta se multiplica cada vez que leemos/vemos un texto consumado en escena. En "Pato Yáñez, o, el gesto nacional" (2009), Fernando Mena reescribe la pregunta, esta vez, de manera paródica:

Pero todo es una gran mentira. Ficción dirían por ahí. Una pregunta que debí haberme hecho antes de entrar a estudiar era ¿para qué es la gran mentira? ¿De que chucha sirve? ¿Pa que sirve el teatro en estos tiempos? ¿Pa Qué? Ahora sé que además de entretener no sirve pa arreglar los problemas reales de la sociedad aunque lo pretenda, en fin. . Porque claro, estamos de acuerdo que mientras yo estoy aquí, gente se muere de frío, se caga de hambre y hace fila en un consultorio pa que le den una hora. Mientras yo estoy aquí en este estado ajeno casi vacío otros se están muriendo, una cabra chica de nueve años se está prostituyendo, a un mapuche le quitan su tierra y un paco golpea a su familia, terremotos, etc. etc. etc. etc.... hay tantas cosas terribles de que hablar y bueno, para eso hay tanta gente que hace teatro. ¿Entonces cual sería mi rol como actor? ¿Cómo hombre de la artes? ¿Cómo hombre especial? (Mena n.p.)

Esta misma idea ronda en otras obras de diverso registro: La chancha (2008), de Luis Barrales, y en Tratando de hacer una obra que cambie el mundo (el delirio final de los últimos románticos), de la compañía La Re-sentida (2009). Ambos trabajos desarrollan una metáfora espacial estructuralmente análoga: en La chancha (2014), son adolescentes encerrados en el cyber-espacio maquinando suicidios masivos; en 
Tratando, un grupo de jóvenes idealistas pasan años atrincherados en un sótano intentando construir un texto teatral que desmonte la política global. Dos ejemplos:

Un foro reúne diariamente a adolescentes en la red. Se trata de "matémonos juntos", sitio virtual para jóvenes con deseos suicidas que por medio de distintos lenguajes buscan trascender a sus propios sentimientos y terminar con sus vidas. Sólo algunos lo conseguirán, quienes a través de distintas pruebas logren demostrar por qué lo merecen. El premio: hacerlo todos juntos. (Barrales 1)

Año 2014 En el último lugar del mundo Luego de la cordillera Bajo tierra o en un lugar muy alejado de la realidad, como lo podría ser un teatro. Seis actores encerrados hace cuatro años, uno ha muerto. (La Resentida 1)

En términos de discurso dramático, estas escenas de malestar desandan el camino de Bobby Meyer. En 1962, los textos de Aguirre, Heiremans y Wolf -Los papeleros, El Tony Chico o Los invasores, respectivamentepresentan, en las diatribas de sus personajes, celebraciones a un arte que abre derroteros hacia territorios desconocidos; a su vez, las acotaciones figuran espacios igualmente amplios: basurales donde se cultiva la revolución, circos populares que traspasan las fronteras del latifundio, piquetes de harapientos que remontan la frontera del Mapocho. Ahora, en cambio, el discurso dramático conoce dos figuras recurrentes: diálogos que reiteran una fútil pregunta retórica (¿para qué sirve el teatro?) y acotaciones que, literalmente, nos sitúan bajo el cielo. En ese registro, el teatro ya no es, ni puede ser, sinónimo de espejo sino, apenas, de encierro, calabozo, cloaca: teatros clausurados (Neva), salas de chat (La chancha), sótanos (Tratando de hacer una obra que cambie el mundo).

\section{Oficio de cloacas}

Quizá la metáfora del teatro como práctica confinada a una cloaca pueda explicarse, también, desde la historia. El desarrollo del capitalismo, que multiplica las opciones de consumo hasta el paroxismo, puede producir inmovilidad sobre los sujetos y arrojarlos a una espiral de ansiedad paralizante. Esta obligatoriedad de las elecciones es un corolario a la pérdida de la tradición que, al liberarnos de lo dado, nos deja también inmóviles 
y desprotegidos (Josipovici 149-50). Los artistas, al perder las imposiciones de la tradición ganan en autonomía, pero pierden la red que podía "protegerlo de las acrobacias de su fantasía" (Steiner 265). Estamos obligados -ioh! rareza histórica- a "crearnos" una identidad, a fabricarnos una función, aunque este sea un oficio de cloacas.

La imposición social de la libertad desplaza el reproche. "El despertar del arte en su autorreferencia durante el siglo XX trae consigo la exigencia complementaria de hacernos cargo de pensar cuál sería la heterorreferencia propia del arte, que hace posible su comunicabilidad" (Bralic 105-6). El deseo de Bralic es librar a las artes del emblema tautológico del ourobouros, la serpiente que se devora a sí misma, emblema de la locura por incomunicación, según Chesterton (40). Que las artes digan algo no sobre sí mismas, sino sobre el mundo, esperamos impacientes. Pesada carga cuando primero deben discernir no cómo son (estadio autorreferencial) sino para qué son (estadio autorreflexivo).

Aquí entra en juego la crítica. Crítica y creación comparten una relación parasitaria en que las vidas anfitrión y de huésped dependen la una de la otra -como habría dicho Joseph Hillis Miller. Antes, la crítica apostaba por relevar los destellos del espejo teatral; hoy día, lucha por salir de su condición de encierro. Estamos en un punto en que la crítica también parece amenazada ante la pérdida de sus antiguas funciones. En palabras de Féral: “[a]demás, ante la fragmentación, la parcelación de las prácticas, la multiplicación que le impide al crítico verlo todo, la crítica ha perdido la función política y social que le daba sentido: la de formar el gusto del público, de orientarlo, de canalizarlo" ("La crítica en tela de juicio: ¿Quién necesita al crítico?” n.p).

Así, arrinconada por la multiplicación de obras y medios de comunicación que, curiosamente, en Chile tienden a homogeneizarse mientras se diversifican, la crítica no hace mucho más que ser un excedente del consumo. Una diferencia, una separación entre público y objeto. La crítica pone de relieve, mediante la opinión, el valor simbólico en la constelación de valores que se pone en juego en el arte. Ahí donde hay uso e intercambio, el ejercicio crítico hace aflorar el excedente simbólico. Sin embargo, esta estrategia no garantiza su especificidad. Actualmente, cuando el espacio simbólico es el que está copado, cuando el intercambio económico se basa progresivamente en esos excedentes sobre el puro consumo, las artes no pueden retener el ejercicio crítico. La esfera de lo "legitimable" de la que hablaba Bourdieu (2002), la cocina, por ejemplo, 
reproduce el juego de tensiones con un grupo crítico que agrega diferencia y por lo tanto valor, a vinos, espumas y ensaladas (30-35).

¿Cómo, entonces, encontrar una labor específica para la crítica? Si se me permite la metáfora de balada pop, haciéndola la compañera del teatro. Si, como dice Beck (1998): "Por una parte; en la búsqueda de una 'vida propia' los hombres y las mujeres son liberados respecto de las formas y asignaciones de roles tradicionales. Por otra parte, las frágiles relaciones sociales empujan a buscar la felicidad en la relación con otra persona" (142). Entonces tanto arte como crítica debieran buscarse uno a otro para establecer esa complicidad dialogante. No se trata de que la crítica responda para qué sirve el teatro, sino de que escuche ese llamado, que no se lance a un público que no puede o no sabe responder. Y que la crítica interrogue de vuelta.

Así las cosas, no se trata de hacer duelo y escándalo por la desaparición de la crítica teatral de los medios impresos de circulación nacional. Tampoco se trata de replicar sus mismos modales en blogs tan irrelevantes como abundantes. Se trata de trasladar la diferencia, la distancia que puede imponer la crítica, no a la relación entre teatro y público, sino entre el teatro y el teatro mismo, permitiéndole mirarse la espalda, saliendo de la trampa de autopromoción a la que lo empuja el sistema de mercado.

Esta búsqueda de sentido ha sido emprendida, de manera loable, por iniciativas como Escuela de Espectadores. Allí, con encomiable oficio, los críticos Javier Ibacache y Soledad Lagos fueron pioneros en la creación de un espacio de diálogo que permita volver a situar el teatro en la agenda de la polis. De manera sugerente, muchas sesiones de esta escuela se celebran en el Centro GAM, otrora sede la UNCTAD y de la Junta Militar que remató la feble democracia criolla. En palabras de Ibacache y Lagos:

Escuela de Espectadores es un programa de análisis y discusión de los distintos lenguajes de las creaciones teatrales que se presentan en Santiago. Abierta en forma gratuita a todo público, en ella se entregan herramientas necesarias para ampliar la lectura, comprensión y valoración de los montajes, con la participación de directores, autores, actores y creadores vinculados a las artes escénicasSe desarrolla a través de ciclos de encuentros por temporada en salas y teatros y se complementa con la publicación de contenidos y registros de audio en este soporte digital. (1-2) 
El trabajo de Lagos e Ibacache nos da un buen pie para ahondar en nuestra discusión sobre la función del teatro, su relación con la polis y las maneras por las que la crítica puede favorecer este diálogo. Sabemos que hay al menos dos maneras en que teatristas y críticos podemos abordar a las audiencia que convoca el teatro: por un lado, una que busca guiar a quiénes ya asisten a las salas a través de orientaciones prácticas (desde normas de comportamiento al interior de una sala hasta referencias culturales que permitan aprehender alguno de los sentidos posibles que puede producir un montaje). ${ }^{12}$ Por otro lado, podemos apostar por ampliar las audiencias habitualmente convocadas a las salas de teatro a través de actividades excéntricas que lleven nuestras prácticas escénicas a espacios inéditos -piénsese, por ejemplo, en las misiones pedagógicas iniciadas por Alejandro Casona en la España pre-franquista y, más tarde, replicadas en Chile por los teatros universitarios.

¿Qué tipo de audiencia queremos construir? Con la experiencia de Escuela de Espectadores, Ibacache y Lagos nos ponen en aviso de algunos tics que padecemos creadores, críticos, espectadores. Nótese la siguiente interacción registrada en Escuela de Espectadores. Ante un diálogo propuesto por Soledad Lagos entre La negra Ester y nuestra memoria teatral, Rosa Ramírez, responde con una frase adversativo que interrumpe el juego retórico:

SOLEDAD LAGOS. Quizá sea sería importante recalcar el hecho de que habría que entenderla como una obra que compone el repertorio del teatro chileno en términos patrimoniales.

ROSA RAMÍREZ. Sí, pero el público que es común y corriente, que tiene ganas de ir a conmoverse, no cuestiona nada, quiere conmoverse. Es como las señoras que no ven mucho teatro, van y te dicen que les gustó todo. . . Todo lo otro, las cosas teóricas que tenemos hoy en día, siento que hacen daño. . . (n.p.)

En la interacción, los participantes parecemos replicar ciertos esquemas conductuales: antes las preguntas de los entrevistadores, los creadores parecen sentirse conminados a explicar el sentido correcto del texto ("en este caso, sin distorsiones teóricas"). Esta genuina “operación

12 Pensamos en una tradición que se remonta, por ejemplo, a la revista Teatro, aliada fiel del Teatro Experimental de la Universidad de Chile. 
de explicación" conlleva estrategias retóricas tendientes a corregir, retrospectivamente, la experiencia del espectador.

En términos generales, dentro del discurso de los creadores advertimos la "atenuación" de elementos materiales considerados prescindibles (escenografía, vestuario), "elipsis" de la incidencia dicción actoral del texto (entonación, fraseo), y "sinécdoque" o reconstitución de sentido a partir de un elemento, la letra antes impresa. De manera complementaria, las preguntas que suceden a la explicación de los creadores son despojadas de su función interrogativa: los creadores parecen considerarlas tesis que deben ser acogidas o descartadas según su grado de adecuación a la explicación precedente.

Naturalmente, este modus operandi evidencia una relación vertical en que la interpretación de la letra que hacen los creadores es más verdadera o correcta que la explicación "fabulosa” del espectador.

Digamos, de paso, que proyectos valiosos y loables como Escuela de Espectadores no solo contribuyen a la creación de audiencias sino, de manera más notable, permiten mapear el lugar de la crítica teatral. En el orden actual, la institucionalidad cultural otorgó un lugar a la práctica teatral pero no hizo lo mismo con la crítica. Después de dos décadas de autoritarismo, el trabajo del comentarista de textos/espectáculos quedó relegado al ámbito periodístico o, cuando no, amparado bajo el alero de la crítica literaria académica. La pregunta por la función del teatro conlleva la pregunta por el lugar del crítico.

Las obras aquí citadas proponen un camino distinto, un camino accional en el que la obra no necesitaría ser explicada porque no constituiría un mensaje sino una acción en el mundo. Esta reacción parece expresar una nostalgia por una convivio-Dubatti dixit- que fuera no un marco para la obra sino la obra misma, como la que reconstruye (¿reconstruye, quizás?) respecto del teatro semiclandestino durante la dictadura.

En este mismo contexto, en el que el teatro en Chile forma a la abrumadora mayoría de sus artistas y sus críticos en programas universitarios y cuyas obras dependen mayoritariamente del financiamiento público. En este escenario de disputa por los fondos del Estado la pregunta por la utilidad, la función y el significado del teatro es una pregunta urgente que no puede evadirse. La respuesta de la academia en Chile ha sido, curiosamente, cederle la respuesta a los creadores, 
compartiendo el control institucional de la interpretación que ejerce la crítica con el propio medio teatral, creando una alianza que homogeniza el campo artístico. En este artículo detectamos un momento en el que los propios creadores, de manera no exenta de ironía, desplazaron la respuesta a la propia obra, volviéndola una negación interrogante. Esta pregunta por la función del teatro desde dentro de la propia obra, esta duda, vuelve a desplazar al espectador volviéndolo innecesario, cayendo en la trampa que según Rancière constituiría la base del teatro moderno, una base ideológica común a movimientos estéticos divergentes.

Con las conmemoraciones del bicentenario, más todavía con las conmemoraciones del Golpe de Estado en 2013, esta pregunta por la función del teatro pareció disolverse por un tiempo. Pero no hay que confundir una ballena sumergida con una inexistente. Sigue ahí, esperando, la pregunta por la relación entre crítica, público y teatro en Chile.

\section{Referencias bibliográficas}

Barba, Eugenio. "The Deep Order Called Turbulence: The Three Faces of Dramaturgy." The Performance Studies Reader. Ed. Henry Bial. New York, Routledge, 2004, pp. 252-61.

Barrales, Luis. "La chancha.”. TS. 2014.

Beck, Ulrich. La sociedad del riesgo: hacia una nueva modernidad. Trad. Jorge Navarro, Daniel Jiménez y María Rosa Borrás. Barcelona, Paidós, 1998.

Bourdieu, Pierre. Campo de poder, campo intelectual. Itinerario de un concepto. Buenos Aires, Montressor, 2002.

Bralic, Cecilia. "La relación entre arte y cultura: acontecimiento y comunicación”. Cátedra de artes, no. 1, 2005, pp.99-107.

Calderón, Guillermo. Neva. Antología de teatro chileno contemporáneo. Eds. María de la Luz Hurtado y Vivian Martínez Tabares. La Habana, Casa de las Américas, 2008.

Chesterton, Gilbert Keith. Ortodoxia. Santiago, Mistral, 2005.

De la Barra, Pedro. “Propósitos.” Teatro, no. 1, 1945, pp. 3-8.

Dubatti, Jorge. Cartografía Teatral. Buenos Aires, Atuel, 2008. 
Féral, Josette. "La crítica en tela de juicio: ¿quién necesita al crítico?” Revista Conjunto, no. 125, 2002, n.p.

Feral, Josette. "La teatralidad: en busca de la especificidad del lenguaje teatral." Teatro, teoría y práctica: más allá de las fronteras. Buenos Aires, Galerna, 2004, pp. 87-106.

Féral, Josette. “Teatro y sociedad: ¿Un nuevo contrato social?”. Investigación Teatral: Revista de la Asociación Mexicana de Investigación Teatral, no. 14, 2003, pp. 9-25.

Ibacache, Javier y Soledad Lagos. Escuela de Espectadores. Ciclos 20082009. Santiago, Escuela de Espectadores de Teatro, 2010.

Ibacache, Javier, y Soledad Lagos. Escuela de espectadores. Santiago, 2010. Josipovici, Gabriel. La terapia de la distancia. Trad. de Carlos Gardini. Barcelona, Andrés Bello, 1998.

Kalawski, Andrés. "Los teatros universitarios no existimos para ser lo que fuimos siempre." La Segunda, 14 jul. 2017, p. 36.

La Resentida. “Tratando de hacer una obra que cambie el mundo.” TS. 2010.

Lehmann, Hans-Thies. “Aspects.” Post-Dramatic Theater. New York, Routledge, 2004, pp. 145-74.

Mena, Fernando. “Pato Yáñez o el Gesto nacional.” TS. 2009.

Müller, Heiner. "El teatro es crisis.” Nexos. Web. 1 oct. 2013.

Ochsenius, Carlos. El estado en la escena: orígenes, formación, desarrollo y crisis de los teatros universitarios de Santiago: 1940-73. Santiago, Universidad Católica, 1982.

Opazo, Cristián. “¿Dónde quedan las humanidades y las artes en un futuro ministerio de ciencia?” El Mercurio. 7 ago. 2017, p. E6.

Opazo, Cristián. “Agorafobia: crítica: universidad.” Aletria vol. 26, no. 1, 2016, pp. 29-47.

Opazo, Cristián. “Luis Alberto Heiremans: las seducciones del paisaje.” Colección Ensayos Críticos: Heiremans. Ed. Cristián Opazo y Carola Oyarzún. Santiago, UC, 2012, pp. 43-75.

“No es (solo) cuestión de dinero: la política pública de los teatros universitarios". III Encuentro Humaniora. BNCH. 19-20 octubre 2016.

Oses, Darío. Machos tristes. Santiago, Planeta, 1992. 
Rancière, Jacques. El espectador emancipado. Trad. De Ariel Dilon. Buenos Aires, Manantial, 2010.

Resentida, La. “Tratando de hacer una obra que cambie el mundo (o el delirio final de los últimos románticos)." TS. 2014.

Reyes, Alfonso. "Aristarco o anatomía de la crítica". Teoría literaria. México, FCE, 2005.

Schwartz,Barry. The Paradox of Choice. Why More Is Less. New York, Ecco, 2004.

Steiner, George. La muerte de la tragedia. Caracas, Monte Ávila, 1970.

Traverso, Enzo. El pasado, instrucciones de uso. Trad. De Almudena González de Cuenca. Madrid, Marcial Pons, 2007.

Vidal, Hernán. Tres argumentaciones postmodernistas. Santiago, Mosquito, 1998.

Wolff, Egon. Flores de papel. 1963. Antología: 100 años de dramaturgia chilena (1910-2010). Ed. María de la Luz Hurtado. Santiago, Comisión Bicentenario, 2010. 